\title{
Terpyridine-Induced Folding of Anisotropic Polyphosphoester Platelets
}

\author{
Tobias P. Haider, Oksana Suraeva, Ingo Lieberwirth, and Frederik R. Wurm*
}

Cite This: ACS Polym. Au 2021, 1, 123-130

Read Online

ABSTRACT: The folding of macromolecules is of great importance in nature. Also in synthetic polymer chemistry, single-chain nanoparticles, i.e. folding synthetic macromolecules, are a current research topic to mimic protein folding and to generate well-defined structures. Here, we present the "folding" of anisotropic polymer platelets to further mimic natural folding processes on the (sub)micrometer scale. We report on the synthesis of terpyridinefunctionalized long-chain polyphosphoesters by acyclic diene metathesis polymerization that can crystallize in dilute solution into anisotropic polymer crystal platelets. As the terpyridine units

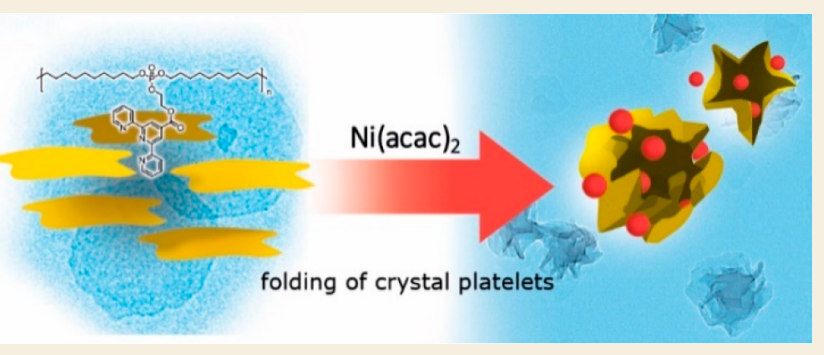
are expelled to the platelet surface, terpyridine-metal interactions could be induced by adding nickel(II) bis(acetylacetonate) $\left(\mathrm{Ni}(\mathrm{acac})_{2}\right)$ to the platelet dispersion in ethyl acetate. These polymer crystals were "folded" to homogeneous nanoparticles with a wrinkled structure, which were visualized by transmission electron microscopy (TEM). The size and size distribution of the obtained assemblies could be altered by varying the concentration of $\mathrm{Ni}(\mathrm{acac})_{2}$. In contrast, no wrinkled structures but rather intrachain crosslinking was observed, when $\mathrm{Ni}(\mathrm{acac})_{2}$ was added to the homogeneous polymer solution before crystallization. We believe that this concept of "folding" anisotropic polymer platelets will further enhance the control of morphologies on (sub)micrometer particles and might be useful for catalysis or separation.

KEYWORDS: crystal engineering, crystal assembly, polyethylene, polyphosphoester, single-chain nanoparticles

\section{INTRODUCTION}

Biomacromolecules such as enzymes effectively function because of their precise and dynamic three-dimensional (3D) architecture. ${ }^{1}$ On inducement by covalent and noncovalent interactions, proteins can undergo guided folding in solution to form complex architectures. ${ }^{2}$ van der Waals interactions, hydrogen bonding, and hydrophobic or electrostatic interactions lead to the protein's secondary structure, including helices, pleated sheets, and turns. ${ }^{1,3}$

In recent years, single-chain polymer nanoparticles (SCPNs) have been presented as synthetic but simplified protein mimics. ${ }^{4}$ SCNPs are formed by collapsed single polymer chains, which can be synthesized from highly diluted solutions by intramolecular covalent (irreversible) or noncovalent (reversible) interactions within the polymer chain. ${ }^{1,4}$ Examining the morphology and the folding process of these simplified synthetic systems is intended to help to understand more complex biomacromolecules. ${ }^{2}$ However, higher-order assemblies of natural polymers are not limited to single polymer chains. Fibrous proteins such as $\alpha$-keratin and collagen are molecules whose secondary structures are their dominant structural motifs. ${ }^{3}$ Collagen, for example, has a triple-helical structure that is further organized into fibrils. To mimic such behavior with synthetic polymers, the assembly or "folding" of colloidal systems can be used. For example, anisotropic assemblies of colloids were achieved by magnetic nanoparticles $^{5}$ or MOFs. ${ }^{6}$

However, to the best of our knowledge, the folding of anisotropic polymer crystallites has not been reported. Such " $2 \mathrm{D}$ ” polymer crystallites represent anisotropic colloids built up of at least thousands of polymer chains, which are obtained by crystallization and typically have thicknesses of ca. 5-10 nm and lateral dimensions of up to several micrometers. These platelets can be prepared from different crystallizable polymers, including both homo- and copolymers, by crystallization from a dilute solution. ${ }^{7-9}$ Several studies were able to create polymer platelets by crystallization-induced self-assembly of block copolymers and polymer blends. ${ }^{10-12}$ Inam et al. showed the application of anisotropic polymer platelets made from polylactide-block-poly(2-dimethylaminoethyl methacrylate) block copolymers as water-in-water emulsifiers. ${ }^{13}$ Polyethylene (PE) also generates anisotropic structures, when it is crystallized from dilute solution. The cooling kinetics influence

Received: June 29, 2021

Published: August 24, 2021 


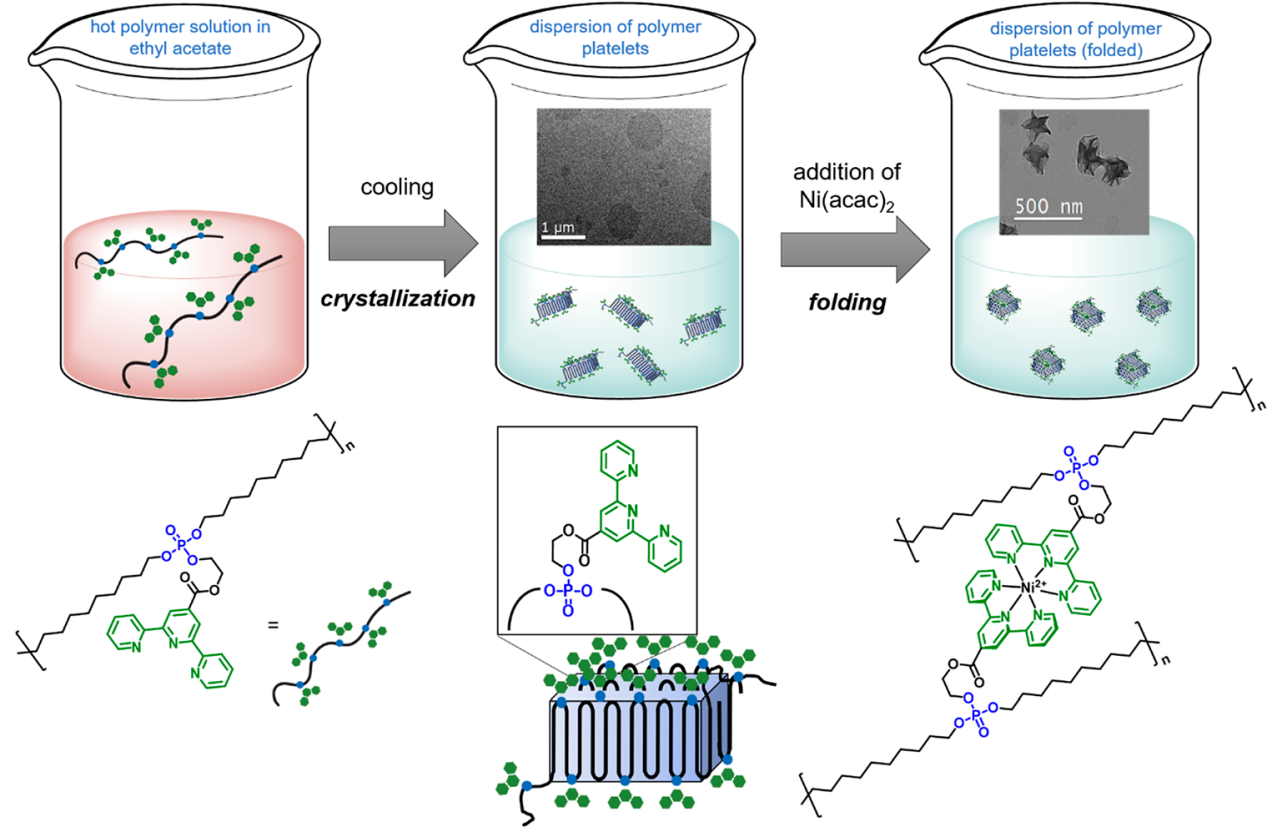

Figure 1. Schematic representation of the experimental procedure used to obtain folded polymer platelets induced by supramolecular interactions.

the thickness and lateral dimension of the crystallites. ${ }^{14,15}$ However, functionalized polyethylene derivatives prepared by either metathesis or coordinative polymerization were found to be able to crystallize in a platelet morphology with a confined thickness due to a regular distance of the functional group in the polymer. ${ }^{16-18}$ Moreover, anisotropic platelets were applied in supported catalysis ${ }^{19}$ and as nanomotors. ${ }^{20}$ Noncovalent interactions between polymer crystal platelets can induce assemblies of a higher order: $\pi-\pi$ interactions between poly $(p-$ phenylenevinylene)-block-poly(2-vinylpyridine) (PPV-b$\mathrm{P} 2 \mathrm{VP}$ ) platelets led to the formation of $2 \mathrm{D}$-square micelles. ${ }^{21}$ Noncovalent metal-ligand interactions are also commonly used to create supramolecular structures. ${ }^{22}$ In particular, chelating ligands are suitable for this purpose, with the tridentate ligand $2,2^{\prime} ; 6^{\prime}, 2^{\prime \prime}$-terpyridine being a prominent example. ${ }^{23}$ Terpyridine forms very stable octahedral complexes with a wide range of different metal ions, including iron, ruthenium, and nickel. The ligand is used for the synthesis of both metallopolymers and 2D polymer networks. ${ }^{24-26}$

Here, we present the synthesis of a polyethylene-like polyphosphate with precisely $20 \mathrm{CH}_{2}$ groups between each phosphate group and pendant terpyridine groups (Figure 1). Dispersions of anisotropic polymer platelets were obtained after crystallization from an ethyl acetate solution. Terpyridine ligands on the platelet surface enabled complexation with nickel cations (after the addition of $\mathrm{Ni}(\mathrm{acac})_{2}$ ), which led to the folding of the polymer platelets. Without previous crystallization, the addition of $\mathrm{Ni}(\mathrm{acac})_{2}$ to a dilute polymer solution led to the formation of small polymer particles by intramolecular interactions of the terpyridines with nickel cations. With this first work, we contribute to a further understanding of how second-order assemblies can be obtained by using anisotropic polymer crystal platelets and nickel-terpyridine interactions (Figure 1). This work sets the basis for the future tuning of polymer crystal engineering using precisely synthesized crystallizable polymers.

\section{RESULTS AND DISCUSSION}

\subsection{Polymer Synthesis and Functionalization}

To obtain anisotropic polymer crystal platelets capable of intraand intermolecular interactions, we synthesized a polyethylenelike polyphosphate with pendant terpyridine groups. In general, polyphosphoesters, and in particular polyphosphates, are a class of versatile polymers: the material properties, solubility, and degradation profile of the polymers strongly depend on the nature of the polymer backbone and the pendant chains. ${ }^{27}$ Furthermore, functional groups can be introduced to the polymer by a variation of the pendant chains. Hydrophobic, PE-like polyphosphates with long methylene spacers between the phosphate groups can be synthesized by acyclic diene metathesis (ADMET) polymerization, ringopening metathesis polymerization, and transesterification. ${ }^{28}$ $\mathrm{ADMET}$ polymerization is a polycondensation reaction of an $\alpha, \omega$-diene under the release of ethylene gas catalyzed by a transition-metal catalyst (e.g., Ru-based Grubbs catalysts). ${ }^{29}$ Symmetrical monomers, which include branches or functional groups, result in polymers with a precise spacing between each branch or functional group, respectively. Previously, we investigated solution-grown polymer crystal platelets of polyethylene-like ADMET polyphosphoesters in detail. ${ }^{18,30,31}$ The polyethylene segments crystallized in a lamellar shape with the phosphoester groups acting as crystallization defects. The length of the polyethylene segment determined the thickness of the lamellae and thus the $z$ dimension of the polymer platelets. ${ }^{18}$ The thickness of the solution-grown lamellar crystals was determined by atomic force microscopy (AFM) and energy-filtered transmission electron microscopy (EFTEM). For the investigated polyphosphate with pendant phenyl groups and with an aliphatic spacer length of $20 \mathrm{CH}_{2}$ groups, a value of ca. $3.2 \mathrm{~nm}$ was obtained by AFM. Furthermore, for this polyphosphate, the phenoxy defects were expelled from the lamellar crystal into the amorphous phase. Thus, we assumed that larger terpyridine groups in the pendant chains will also be expelled from the polymer crystal. On consideration that a chain fold is associated with every 

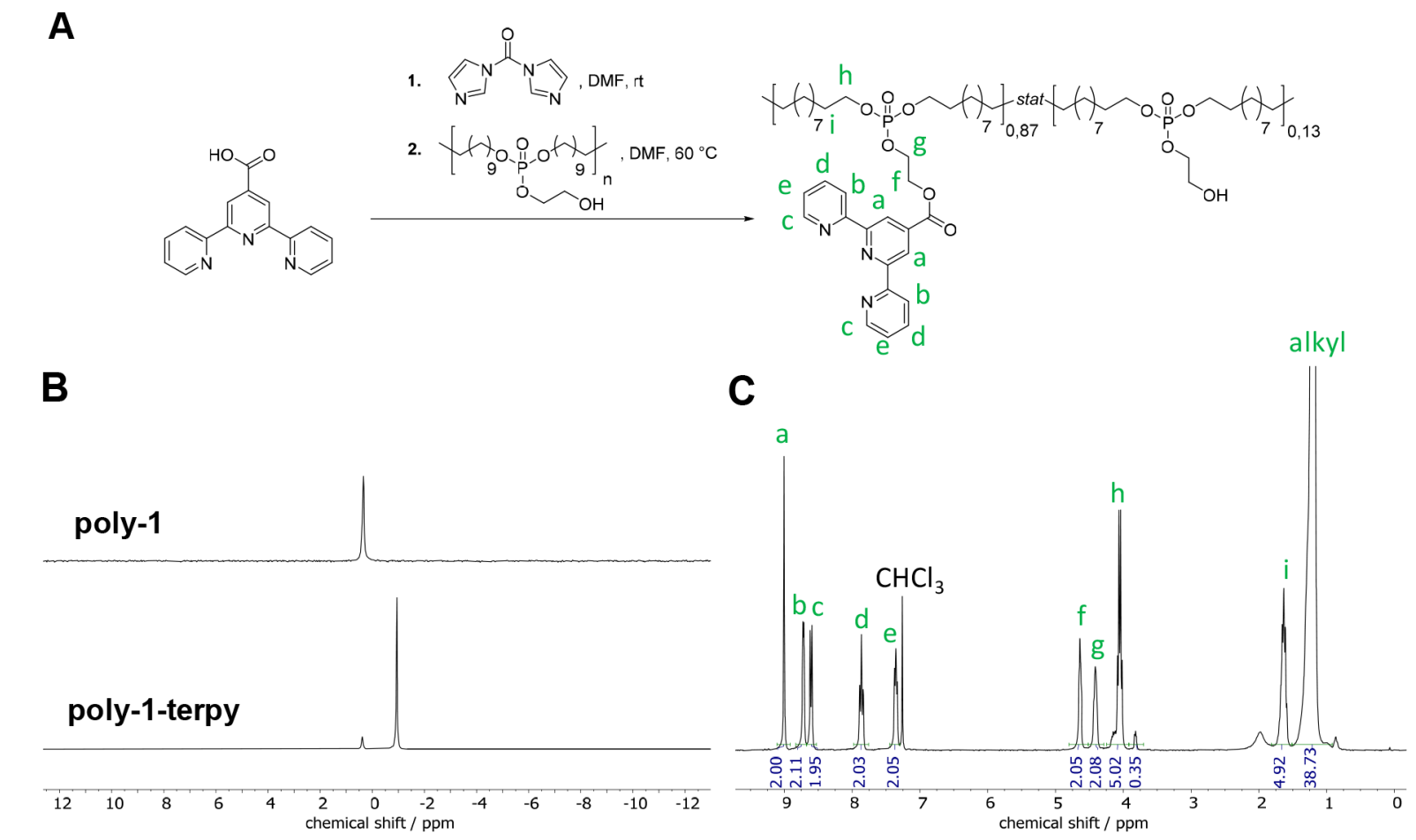

Figure 2. (A) Synthesis of poly-1-terpy via carboxylic acid activation by carbonyldiimidazole (CDI). (B) ${ }^{31} \mathrm{P} \mathrm{NMR}(121 \mathrm{MHz}$ at $298 \mathrm{~K}$, in CDCl 3 ) of poly-1 (top) and poly-1-terpy (bottom). (C) ${ }^{1} \mathrm{H} \mathrm{NMR} \mathrm{(300} \mathrm{MHz}$ at $298 \mathrm{~K}$, in $\mathrm{CDCl}_{3}$ ) of poly-1-terpy.

second lattice point, the surface area for the constituent on the crystal surface can be calculated to be ca. $4.8 \AA$ in the (010) direction and ca. $8 \AA$ in the (110) direction of an ideal crystal structure. $^{18,32}$ On the assumption of rotational freedom of the terpyridine groups and the available area at every second chain fold, the terpyridine functional groups are expected to have enough space on the polymer crystal surface and are accessible to further functionalization.

For the starting material, we used the long-chain polyphosphate poly-1 with $20 \mathrm{CH}_{2}$ groups between each phosphate group and an ethoxy hydroxyl side chain. Functionalization was accessible through the primary alcohol in the pendant chain, while the precise spacing between the phosphate groups ensured an even distribution of the functional groups along the surface of the resultant crystal platelets. The monomer was obtained in a two-step reaction of $\mathrm{POCl}_{3}$ with 2-(benzyloxy)ethanol and 10-undecen-1-ol. After ADMET polymerization in bulk using the first-generation Grubbs catalyst, Pd-catalyzed hydrogenation was performed to give fully saturated poly-1 with free hydroxyl groups in the pendant chains.

The terpyridine ligand was covalently attached to the polyphosphate side chain via an ester linkage. In a one-pot reaction, first an active ester of $2,2^{\prime}: 6^{\prime}, 2^{\prime \prime}$-terpyridine- $4^{\prime}$ carboxylic acid was formed by the reaction with carbonyldiimidazole (CDI). This active ester readily reacted with poly-1 upon addition to give poly-1-terpy with the cleavage of imidazole (Figure 2). The reaction was conducted at $60{ }^{\circ} \mathrm{C}$ to overcome solubility restrictions. poly-1-terpy was purified by repeated precipitation into cold methanol to give a solid colorless polymer with a $48 \%$ yield.

poly-1-terpy was analyzed by NMR spectroscopy. Figure $2 \mathrm{~B}$ shows an overlay of the ${ }^{31} \mathrm{P}$ NMR spectra of poly-1 and poly1-terpy: the initial resonance at $0.47 \mathrm{ppm}$, corresponding to poly-1, disappeared almost entirely, while an intense new signal at $-0.93 \mathrm{ppm}$ indicated a successful covalent attachment of the terpyridine group to the polymer. Additionally, ${ }^{1} \mathrm{H}$ NMR spectroscopy of the same polymer shows new resonances between 7.30 and $9.01 \mathrm{ppm}$, which were assigned to the terpyridine groups attached to the polymer (Figure 2C). The integration of all signals in ${ }^{1} \mathrm{H}$ and ${ }^{31} \mathrm{P}$ NMR spectra verified that a degree of functionalization of ca. $85 \%$ was achieved, despite the high steric bulk of the terpyridine group. When the esterification reaction was repeated, a degree of functionalization of ca. 60\% was achieved for a second entry (Figure S3). The molecular weight of poly-1-terpy was determined by size exclusion chromatography in THF relative to a PS standard (Figure S1). Values of $M_{\mathrm{n}}=4100 \mathrm{~g} \mathrm{~mol}^{-1}$ and $M_{\mathrm{w}}=17000 \mathrm{~g}$ $\mathrm{mol}^{-1}$ were obtained. In comparison to the starting material, both values dropped after functionalization (poly-1: $M_{\mathrm{n}}=$ $7400 \mathrm{~g} \mathrm{~mol}^{-1}, M_{\mathrm{w}}=21000 \mathrm{~g} \mathrm{~mol}^{-1}$ ). Furthermore, an intense tailing of the SEC trace of poly-1-terpy indicated a possible interaction between the polymer and the column material. In contrast to poly-1, the elugram of poly-1-terpy shows an intense UV trace, which further proved the covalent linkage of the UV-active terpyridine group to the polymer backbone. The thermal properties of poly-1-terpy were examined by differential scanning calorimetry (Figure S2). A glass transition temperature $\left(T_{\mathrm{g}}\right)$ of $19{ }^{\circ} \mathrm{C}$ and a melting point $\left(T_{\mathrm{m}}\right)$ of $66^{\circ} \mathrm{C}$ with a melting enthalpy $\Delta H_{\mathrm{m}}$ of $-36.2 \mathrm{~J} \mathrm{~g}^{-1}$ were observed. The $T_{\mathrm{m}}$ value decreased by $20{ }^{\circ} \mathrm{C}$ in comparison to poly- $1\left(T_{\mathrm{m}}\right.$ $=86{ }^{\circ} \mathrm{C}$ ) due to the absence of hydrogen bonding. By a comparison of the $\Delta H_{\mathrm{m}}$ value of poly-1-terpy to that of $100 \%$ crystalline polyethylene $\left.\left(\Delta H_{\mathrm{m}}=293 \mathrm{~J} \mathrm{~g}^{-1}\right)\right)^{33}$ the crystallinity of the polymer was calculated. The obtained value of $12 \%$ crystallinity was lower in comparison to poly-1 (35\%) and a long-chain polyphosphate with the same aliphatic spacer length but with an ethoxy pendant chain $(26 \%))^{34}$ This indicates the strong effect of the bulky terpyridine groups on the crystallization behavior of the polymer. 
2.2. Solution-Grown Polymer Platelets from poly-1 and poly-1-terpy

Anisotropic polymer crystal platelets can be prepared by crystallization of PE-like polymers from their dilute solutions. ${ }^{30}$ For the crystallization of poly-1-terpy, entry 2 was used with a degree of terpyridine functionalization of ca. $60 \%$. Solutions of poly-1-terpy in ethyl acetate with concentrations of 0.1 orand $1 \mathrm{mg} \mathrm{mL}{ }^{-1}$, respectively, were slowly cooled from $70{ }^{\circ} \mathrm{C}$ to room temperature (ca. $23{ }^{\circ} \mathrm{C}$ ) over a period of $24 \mathrm{~h}$ to give dispersions of polymer platelets. Transmission electron microscopy (TEM) showed the formation of polymer platelets similar to those of other long-chain polyphosphoesters published earlier. ${ }^{30}$ With an identical aliphatic spacer length of $20 \mathrm{CH}_{2}$ groups between each phosphate group, the thickness of the polymer platelets had been determined to be in the range of several nanometers. ${ }^{30}$ On comparison of the morphologies of platelets crystallized from ta solution of poly1-terpy to solution-grown crystal platelets of the initial poly-1, monolayer crystals with similar shape and size were observed despite the high steric bulk of the terpyridine group and the reduced crystallinity of poly-1-terpy (Figure S4). Similarly to other phosphate groups in long-chain polyphosphoesters, we expect the terypridine groups to be expelled from the crystal, thus being accessible for metal-ligand supramolecular interactions. The TEM images were used to analyze the size and size distribution of the platelets using ImageJ software (Figure 3 and Figure S5). From the data, we calculated the

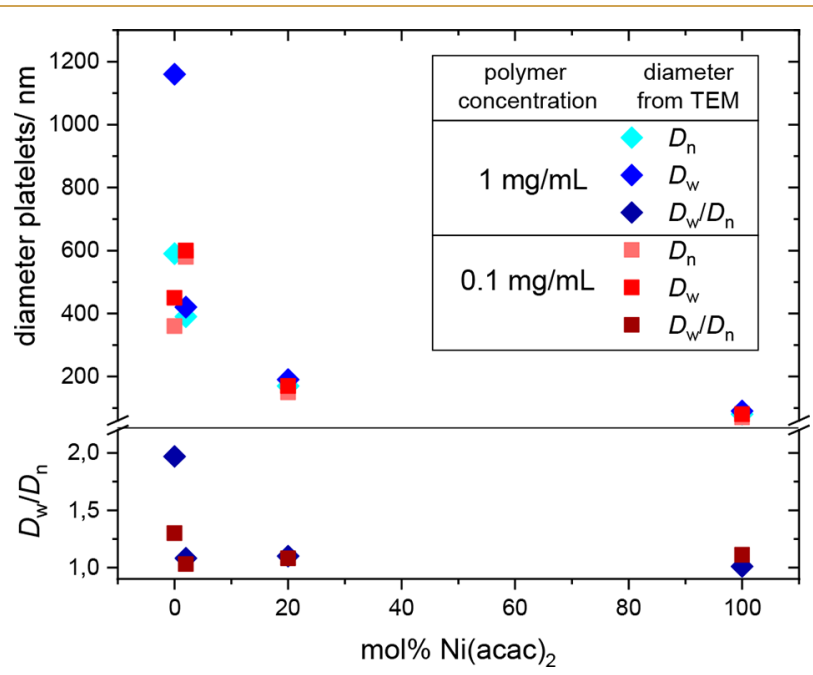

Figure 3. Diameters of the polymer platelets without the addition of $\mathrm{Ni}(\mathrm{acac})_{2}$ and after the addition of 2,20 , or $100 \mathrm{~mol} \%$ of $\mathrm{Ni}(\mathrm{acac})_{2}$ in comparison to the terpyridine units $\left(D_{\mathrm{n}}\right.$ and $D_{\mathrm{w}}$ were determined from an analysis of TEM images).

number-average platelet diameter $D_{\mathrm{n}}$ and weight-average platelet diameter $D_{\mathrm{w}}$ as well as the dispersity $D_{\mathrm{w}} / D_{\mathrm{n}}$ (see Table S1 and Figure 3). ${ }^{9}$ We found that the lateral dimensions of the platelets depended on the concentration of the initial polymer solutions: for an initial polymer concentration of $1 \mathrm{mg}$ $\mathrm{mL}^{-1}$, platelets with diameters of $D_{\mathrm{n}}=590 \mathrm{~nm}$ and $D_{\mathrm{w}}=1.16$ $\mu \mathrm{m}$ were obtained, exhibiting a relatively broad size distribution $D_{\mathrm{w}} / D_{\mathrm{n}}$ of ca. 2 (Figures 3 and 4 ). Platelets obtained from solutions with a concentration of $0.1 \mathrm{mg} \mathrm{mL}^{-1}$ were significantly smaller $\left(D_{\mathrm{n}}=360 \mathrm{~nm}\right)$ with a narrower size distribution $\left(D_{\mathrm{w}} / D_{\mathrm{n}}=1.25\right)$.
To induce a supramolecular interaction between the terpyridine groups on the surface of the polymer platelets, $\mathrm{Ni}(\mathrm{acac})_{2}$ dissolved in ethyl acetate was added to dispersions of poly-1-terpy crystal platelets also in ethyl acetate. $\mathrm{Ni}^{2+}$ ions form octahedral complexes with two terpyridine ligands (Figure 1$){ }^{23}$ The ratio of $\mathrm{Ni}(\mathrm{acac})_{2}$ to terpyridine units was varied from 2 to 20 and $100 \mathrm{~mol} \%$ with respect to the terpyridine units in the polymer. At both initial polymer concentrations and at all $\mathrm{Ni}^{2+}$ ratios, the complexation of $\mathrm{Ni}^{2+}$ by terpyridine-functionalized platelets resulted in a folding of the platelets into wrinkled nanoparticles (Figure 4). Due to the folding, the diameters of all nanoparticles decreased in comparison to those for the flat initial platelets except for the sample with $2 \mathrm{~mol} \%$ of $\mathrm{Ni}(\mathrm{acac})_{2}$ and $0.1 \mathrm{mg} \mathrm{mL}^{-1}$ initial polymer concentration.

$D_{\mathrm{n}}$ decreased with an increasing concentration of $\mathrm{Ni}^{2+}$ ions, down to $70 \mathrm{~nm}$ for the sample with $100 \mathrm{~mol} \%$ of $\mathrm{Ni}(\mathrm{acac})_{2}$ and $0.1 \mathrm{mg} \mathrm{mL}^{-1}$ initial polymer concentration. From these data, it can be assumed that the addition of $\mathrm{Ni}^{2+}$ ions resulted in the complexation of two terpyridine units of the same polymer platelet and that, by an increase in the number of metal ions, a higher number of ligand-metal complexes were formed, resulting in a higher degree of folding of the platelets. For samples with 2 and $20 \mathrm{~mol} \%$ of $\mathrm{Ni}(\mathrm{acac})_{2}$ added, the amount of $\mathrm{Ni}^{2+}$ present was not enough to form completely spherical folded assemblies. Thus, the lateral sizes of the obtained conformations were larger in comparison to samples with $100 \mathrm{~mol} \%$ of $\mathrm{Ni}(\mathrm{acac})_{2}$ added. Also, there is the probability of the formation of ligand-metal complexes between two different crystals (intercrystal interactions); thus, the obtained assemblies may contain several different platelets. Platelets from the initial crystal dispersion with a size below $200 \mathrm{~nm}$ presumably took part in intercrystal assemblies, with larger platelets explaining why no very small folded crystal formation could be observed. This may also explain the increased $D_{\mathrm{n}}$ and $D_{\mathrm{w}}$ values for the sample with $2 \mathrm{~mol} \%$ of $\mathrm{Ni}(\mathrm{acac})_{2}$ and $0.1 \mathrm{mg} \mathrm{mL}^{-1}$ polymer concentration in comparison to the initial polymer platelets, as no small assemblies below $300 \mathrm{~nm}$ could be detected. In comparison to the initial platelets, the dispersity of the platelet size distribution decreased significantly for each experiment after the addition of $\mathrm{Ni}(\mathrm{acac})_{2}$. The narrowing of the size distributions indicated that for each concentration the size diameter/surface area of the resulting tertiary structures converged to an optimum value for the given conditions.

In general, the folding process induced by the supramolecular interactions provided a certain flexibility of the crystal platelets, allowing them to deform. ${ }^{35}$ Furthermore, the formation of higher-order assemblies indicated a successful surface functionalization of the crystal platelets and the accessibility of these groups for metal-ligand interactions. The diffraction pattern of the crystal platelets confirmed that the samples were still crystalline after the addition of the metal salt solutions. However, the diffraction pattern was less prominent in comparison to the initial diffraction pattern of poly-1-terpy platelets in ethyl acetate (Figure S6). While for the initial poly-1-terpy polymer the structure of monolayer crystals can be determined from the position of the diffraction spots, the multilayered nature of the obtained folded structures and chaotic arrangement of these layers led to a less prominent and broad diffraction pattern. 


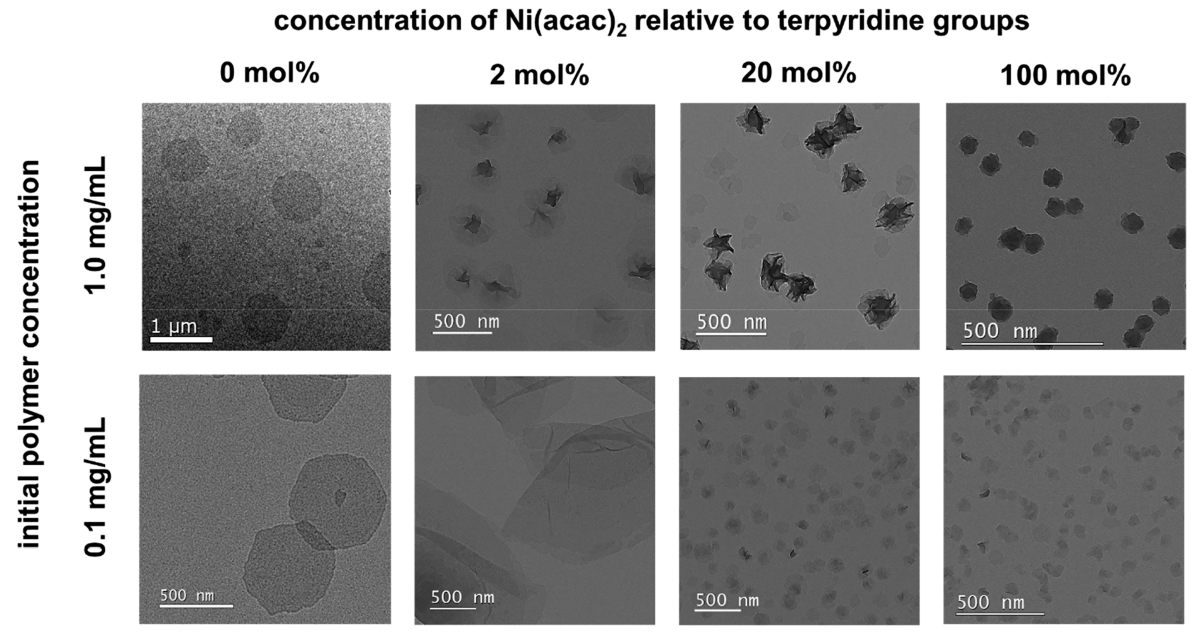

Figure 4. TEM bright-field images of poly-1-terpy polymer platelets prepared by crystallization from ethyl acetate solution and after addition of different concentrations of $\mathrm{Ni}(\mathrm{acac})_{2}$. Images on the left show the initial polymer crystals.

\subsection{Complex Formation of poly-1-terpy in Solution}

As a comparison to the folding of the polymer platelets after crystallization from solution, we investigated the folding of dissolved poly-1-terpy in the presence of $\mathrm{Ni}(\mathrm{acac})_{2}$. poly-1terpy was dissolved in chloroform at a concentration typical for the formation of single-chain nanoparticles $(0.03 \mathrm{mg}$ $\mathrm{mL}^{-1}$ ), and $\mathrm{Ni}(\mathrm{acac})_{2}$ was added to the solution (an equimolar ratio of $\mathrm{Ni}^{2+}$ and terpyridine ligands was used in the experiment). Afterward, the mixture was visualized via TEM imaging and no crystal platelets were formed, indicating that the terpyridine-nickel interactions took place randomly and prevented the resulting organometallic polymer from crystallizing into lamellar crystals (Figure S7).

\section{CONCLUSION AND OUTLOOK}

Despite high interest in the formation of single-chain nanoparticles and 2D materials separately, these two research areas had not been rarely combined. Here, we have shown for the first time the folding of anisotropic polyphosphoester platelets ("2D platelets") into wrinkled particles by intracrystal interactions between terpyridine units on the platelet surface and nickel cations. We prepared a long-chain polyphosphoester with $20 \mathrm{CH}_{2}$ groups between the phosphate units by acyclic diene metathesis polymerization and subsequent hydrogenation. As the phosphate units can be functionalized at their pendant ester positions, it was possible to introduce pendant terpyridine groups. Solution-grown anisotropic platelets with mean average diameters of $D_{\mathrm{n}}=380$ and $590 \mathrm{~nm}$ were obtained from two polymer solutions at 0.1 and $1 \mathrm{mg} \mathrm{mL}^{-1}$ concentrations, respectively. After the addition of $\mathrm{Ni}(\mathrm{acac})_{2}$, the accessible terpyridine groups on the crystal surface enabled the formation of higher-order assemblies by supramolecular interactions. This complexation induced the folding of the platelets, resulting in wrinkled nanoparticles with significantly smaller diameters and narrower size distribution in comparison to the initial platelets. Variation of the metal ion concentration allowed control over the size of the obtained structures. The crystallinity of the platelet assemblies was confirmed by diffraction patterns from TEM. We believe that this first example of the formation of folded nanoplatelets is a step toward extended mimicking of natural folding processes with synthetic polymers, which might lead to unprecedented properties: e.g., in catalytic applications.

\section{EXPERIMENTAL SECTION}

\subsection{Materials}

All reagents were purchased from Sigma-Aldrich, Carl Roth, and Alfa Aesar and were used without further purification. $\mathrm{CDCl}_{3}$ was purchased from Sigma-Aldrich.

\subsection{Instrumentation and Characterization Techniques}

For nuclear magnetic resonance (NMR) analysis ${ }^{1} \mathrm{H},{ }^{13} \mathrm{C}$, and ${ }^{31} \mathrm{P}$ NMR spectra of the monomers were recorded on a Bruker AVANCE III 300, 400, 500, or $700 \mathrm{MHz}$ spectrometer. All spectra were measured in $\mathrm{CDCl}_{3}$ at $298 \mathrm{~K}$. The spectra were calibrated against the solvent signal and analyzed using MestReNova 12 from Mestrelab Research SL. Size exclusion chromatography (SEC) measurements were performed in THF on an Agilent Technologies 1260 instrument consisting of an autosampler, pump, and column oven. The column set consists of three columns: SDV $10^{6} \AA$, SDV $10^{4} \AA$, and SDV $500 \AA$ (PSS Standards Service GmbH, Mainz, Germany), all of $300 \times 8 \mathrm{~mm}$ and $10 \mu \mathrm{m}$ average particle size were used at a flow rate of $1.0 \mathrm{~mL} /$ min and a column temperature of $30{ }^{\circ} \mathrm{C}$. The injection volume was $100 \mu \mathrm{L}$. Detection was accomplished with an RI detector (Agilent Technologies) and UV detector. The data acquisition and evaluation were performed using PSS WINGPC UniChrom (PSS Polymer Standards Service GmbH, Mainz, Germany). Calibration was carried out by using polystyrene provided by PSS Polymer Standards Service $\mathrm{GmbH}$ (Mainz, Germany). The thermal properties of the synthesized polymers were measured by differential scanning calorimetry (DSC) on a Mettler Toledo DSC 823 calorimeter. Three scanning cycles of heating/cooling were performed under a nitrogen atmosphere (30 $\mathrm{mL} / \mathrm{min}$ ) with a heating and cooling rate of $10{ }^{\circ} \mathrm{C} / \mathrm{min}$. The crystal morphology was determined using an FEI Tecnai F20 transmission electron microscope operated at an acceleration voltage of $200 \mathrm{kV}$. The bright-field (BF) technique was used for measurements. The size of the crystal platelets was determined using ImageJ software. Histograms of the diameter distribution were constructed using Origin Pro 9. From these data, values of $D_{\mathrm{n}}$ and $D_{\mathrm{w}}$ were calculated as shown below $(D$, the diameter of the platelet; $N$, number):

$$
D_{\mathrm{n}}=\frac{\sum_{i=1}^{n} N_{i} D_{i}}{\sum_{i=1}^{n} N_{i}} D_{\mathrm{w}}=\frac{\sum_{i=1}^{n} N_{i} D_{i}^{2}}{\sum_{i=1}^{n} N_{i} D_{i}}
$$

\subsection{Monomer and Polymer Synthesis}

To prevent any contamination with iron during the reaction, no syringes with metal needles were used during the reaction. Instead, all reagents were added in solution via plastic or glass pipettes.

4.3.1. Synthesis of 2-(Benzyloxy)ethyl Phosphorodichloridate (1a). $\mathrm{POCl}_{3}(37.0 \mathrm{~g}, 0.24 \mathrm{~mol})$ was dissolved in $100 \mathrm{~mL}$ of dry toluene and cooled to $0^{\circ} \mathrm{C}$. A solution of 2-(benzyloxy)ethanol (5.15 
g, $33.8 \mathrm{mmol}$ ) and $\mathrm{NEt}_{3}(3.79 \mathrm{~g}, 37.5 \mathrm{mmol})$ in $25 \mathrm{~mL}$ of dry toluene was added dropwise within $1 \mathrm{~h}$. A white precipitate $\left(\mathrm{NEt}_{3} \cdot \mathrm{HCl}\right)$ formed during the reaction. The reaction mixture was stirred overnight at room temperature. Filtration under an argon atmosphere was performed, and the residual $\mathrm{POCl}_{3}$ and solvent were removed under reduced pressure. The obtained orange oil was used without further purification for the next step ( $82 \%$ yield).

${ }^{1} \mathrm{H}$ NMR $\left(300 \mathrm{MHz}, \mathrm{CDCl}_{3}\right): \delta 7.46-7.26(\mathrm{~m}, 5 \mathrm{H}$, aryl), $4.60(\mathrm{~s}$, $\left.2 \mathrm{H}, \mathrm{Ph}-\mathrm{CH}_{2}-\mathrm{O}-\right), 4.47\left(\mathrm{~m}, 2 \mathrm{H}, \mathrm{POCl}_{2}-\mathrm{O}-\mathrm{CH}_{2}-\right), 3.77(\mathrm{~m}, 2 \mathrm{H}$, $\left.\mathrm{POCl}_{2}-\mathrm{O}-\mathrm{CH}_{2}-\mathrm{CH}_{2}-\right) .{ }^{13} \mathrm{C}$ NMR $\left(75 \mathrm{MHz}, \mathrm{CDCl}_{3}\right): \delta 128.51$, 127.98, 127.75, 73.39, 70.72, 67.68. ${ }^{31} \mathrm{P}$ NMR $\left(121 \mathrm{MHz} \mathrm{CDCl}_{3}\right): \delta$ 7.82.

4.3.2. Synthesis of 2-(Benzyloxy)ethyl Bis(undec-10-en-1yl)phosphate (1). 10-Undecen-1-ol (9.12 g, $53.6 \mathrm{mmol})$ and triethylamine $(5.67 \mathrm{~g}, 56.0 \mathrm{mmol})$ were dissolved in $55 \mathrm{~mL}$ of dry toluene and cooled to $0{ }^{\circ} \mathrm{C}$. A solution of $1 \mathrm{a}(7.6 \mathrm{~g}, 28.3 \mathrm{mmol})$ dissolved in $40 \mathrm{~mL}$ of dry toluene was added dropwise within $1 \mathrm{~h}$. A white precipitate indicated the formation of $\mathrm{NEt}_{3} \cdot \mathrm{HCl}$. After the addition was completed, the reaction mixture was further stirred at room temperature for 7 days. The ongoing reaction was monitored by ${ }^{31} \mathrm{P}$ NMR. The reaction mixture was filtered and washed with $0.1 \mathrm{M}$ $\mathrm{NaOH}$ solution to remove any pyrophosphate side products. The aqueous phase was extracted with petroleum ether several times before the organic phases were combined and washed with a slightly acidic $\mathrm{HCl} / \mathrm{NaCl}$ solution. The organic phase then was dried over $\mathrm{MgSO}_{4}$ and filtered, and the solvent was removed under reduced pressure. Column chromatography was performed with a Büchi Reverlis PREP system using petroleum ether and ethyl acetate as the eluent in alternating ratios $\left(R_{\mathrm{f}}=0.64\right.$ in petroleum ether/ethyl acetate $2 / 1)$. The purified product was obtained as a viscous oil $(8.2 \mathrm{~g}, 57 \%$ yield).

${ }^{1} \mathrm{H}$ NMR $\left(300 \mathrm{MHz}, \mathrm{CDCl}_{3}\right): \delta 7.40-7.25(\mathrm{~m}, 5 \mathrm{H}$, aryl), $5.81(\mathrm{~m}$, $\left.2 \mathrm{H},-\mathrm{CH}=\mathrm{CH}_{2}\right), 5.05-4.84\left(\mathrm{~m}, 4 \mathrm{H},-\mathrm{CH}=\mathrm{CH}_{2}\right), 4.57(\mathrm{~s}, 2 \mathrm{H}$, $\left.\mathrm{Ph}-\mathrm{CH}_{2}-\mathrm{O}-\right)$, $4.25-4.14\left(\mathrm{~m}, 2 \mathrm{H},-\mathrm{O}-\mathrm{PO}_{3}-\mathrm{CH}_{2}-\mathrm{CH}_{2}-\mathrm{OBn}\right)$, $4.02\left(\mathrm{q}, J=6.8 \mathrm{~Hz}, 4 \mathrm{H},-\mathrm{O}-\mathrm{PO}_{3}-\mathrm{CH}_{2}-\right), 3.69(\mathrm{t}, J=4.8 \mathrm{~Hz}, 4 \mathrm{H}$, $\left.-\mathrm{CH}_{2}-\mathrm{CH}_{2}-\mathrm{OBn}\right), 2.03\left(\mathrm{q}, J=7.0 \mathrm{~Hz}, 4 \mathrm{H},-\mathrm{CH}_{2}-\mathrm{CH}=\right), 1.64(\mathrm{q}$, $\left.J=6.8 \mathrm{~Hz}, 4 \mathrm{H},-\mathrm{OPO}_{3}-\mathrm{CH}_{2}-\mathrm{CH}_{2}\right), 1.50-1.24(\mathrm{~m}, 2 \mathrm{H}$, alkyl $) .{ }^{13} \mathrm{C}$ NMR $\left(75 \mathrm{MHz}, \mathrm{CDCl}_{3}\right): \delta 139.18,137.89,128.40,127.71(\mathrm{~d}, J=3.6$ $\mathrm{Hz}), 114.14,73.21,68.98(\mathrm{~d}, J=7.0 \mathrm{~Hz}), 67.85(\mathrm{~d}, J=5.9 \mathrm{~Hz}), 66.50$ $(\mathrm{d}, J=5.9 \mathrm{~Hz}), 33.80,30.26(\mathrm{~d}, J=6.9 \mathrm{~Hz}), 29.91-28.48(\mathrm{~m}), 25.43$. ${ }^{31} \mathrm{P}$ NMR $\left(121 \mathrm{MHz}^{\mathrm{CDCl}}{ }_{3}\right): \delta-0.69$. APCI MS: $\mathrm{m} / z$ 537.6 [M+ $\mathrm{H}]^{+}$.

4.3.3. ADMET Polymerization of 1 and Subsequent Hydrogenation. Monomer $1(1.14 \mathrm{~g}, 2.1 \mathrm{mmol})$ was charged in a $25 \mathrm{~mL}$ Schlenk tube and degassed by three consecutive argon/vacuum cycles. A $17 \mathrm{mg}$ portion of first-generation Grubbs catalyst $(0.1 \mathrm{~mol} \%)$ was added under an argon stream, and the mixture was kept stirring for 5 $\mathrm{min}$. The system was connected to a vacuum pump $\left(4 \times 10^{-1} \mathrm{mbar}\right)$, and intensive bubbling indicated the start of the polymerization as ethylene gas evolved. After $5 \mathrm{~min}$, the Schlenk tube was placed in an oil bath at $60{ }^{\circ} \mathrm{C}$ and was kept there overnight. The highly viscous mixture was allowed to cool before a second portion of firstgeneration Grubbs catalyst was added as well as $0.8 \mathrm{~mL}$ of $\mathrm{CH}_{2} \mathrm{Cl}_{2}$ to dissolve the polymer. The polymerization was continued at $60^{\circ} \mathrm{C}$ and $4 \times 10^{-1}$ mbar for another $24 \mathrm{~h}$. After the mixture was cooled, $5 \mathrm{~mL}$ of $\mathrm{CH}_{2} \mathrm{Cl}_{2}$ and $150 \mu \mathrm{L}$ of ethyl vinyl ether were added to quench the catalyst. The solution turned from purple to orange, indicating the formation of the Fischer carbene complex of the Grubbs catalyst with ethyl vinyl ether. To remove this complex, the polymer was precipitated from methanol. After centrifugation, the product was isolated as a highly viscous, honey-like, dark brown oil in quantitative yield.

${ }^{1} \mathrm{H}$ NMR (300 MHz, $\left.\mathrm{CDCl}_{3}\right): \delta 7.38-7.27(\mathrm{~m}, 5 \mathrm{H}$, aryl), $5.36(\mathrm{~m}$, $2 \mathrm{H},-\mathrm{CH}=\mathrm{CH}-), 4.57\left(\mathrm{~s}, 2 \mathrm{H}, \mathrm{Ph}-\mathrm{CH}_{2}-\mathrm{O}-\right), 4.25-4.10(\mathrm{~m}, 2 \mathrm{H}$, $\left.-\mathrm{O}-\mathrm{PO}_{3}-\mathrm{CH}_{2}-\mathrm{CH}_{2}-\mathrm{OBn}\right), 4.01(\mathrm{p}, J=6.8 \mathrm{~Hz}, 4 \mathrm{H}, \mathrm{q}, J=6.8 \mathrm{~Hz}$, $\left.4 \mathrm{H},-\mathrm{O}-\mathrm{PO}_{3}-\mathrm{CH}_{2}-\right), 3.68\left(\mathrm{t}, J=8.2,6.6 \mathrm{~Hz}, 2 \mathrm{H},-\mathrm{CH}_{2}-\mathrm{CH}_{2}-\right.$ $\mathrm{OBn}), 1.96\left(\mathrm{~m}, 4 \mathrm{H},-\mathrm{CH}_{2}-\mathrm{CH}=\right), 1.64\left(\mathrm{~m}, 4 \mathrm{H},-\mathrm{OPO}_{3}-\mathrm{CH}_{2}-\right.$ $\left.\mathrm{CCH}_{2}\right), 1.28\left(\mathrm{~m}, 20 \mathrm{H}\right.$, alkyl). ${ }^{13} \mathrm{C}$ NMR $\left(75 \mathrm{MHz} \mathrm{CDCl}_{3}\right): \delta 137.89$, $130.32,129.86,128.40,127.70,118.16,73.20,68.98(\mathrm{~d}, J=7.0 \mathrm{~Hz})$, $67.85(\mathrm{~d}, J=6.2 \mathrm{~Hz}), 66.49(\mathrm{~d}, J=5.8 \mathrm{~Hz}), 32.63,30.28(\mathrm{~d}, J=6.9$
$\mathrm{Hz}), 29.77-28.83(\mathrm{~m}), 27.24,25.44 .{ }^{31} \mathrm{P} \mathrm{NMR}\left(121 \mathrm{MHz}, \mathrm{CDCl}_{3}\right): \delta$ -0.70 .

4.3.4. Hydrogenation. In a glass vessel equipped with a stirring bar, $1.97 \mathrm{~g}(3.7 \mathrm{mmol})$ of the previously obtained polymer was dissolved in $90 \mathrm{~mL}$ of THF. Residual oxygen was removed by bubbling argon through the solution for $10 \mathrm{~min}$. A $1.45 \mathrm{~g}$ portion of $20 \mathrm{wt} \% \mathrm{Pd}(\mathrm{OH})_{2} / \mathrm{C}$ was added, and the glass vessel was placed in an ultrasonication bath to achieve better dispersion of the catalyst in the solution. Afterward, the glass vessel was charged in a $250 \mathrm{~mL} \mathrm{ROTH}$ autoclave and the hydrogenation was performed at 80 bar of $\mathrm{H}_{2}$ at room temperature for $16 \mathrm{~h}$. After filtration, the polymer was precipitated from methanol and isolated to obtain a solid, white polymer in quantitative yield.

${ }^{1} \mathrm{H}$ NMR $\left(300 \mathrm{MHz}, \mathrm{CDCl}_{3}\right): \delta 4.15(\mathrm{dt}, J=9.3,4.1 \mathrm{~Hz}, 2 \mathrm{H},-\mathrm{O}-$ $\left.\mathrm{PO}_{3}-\mathrm{CH}_{2}-\mathrm{CH}_{2}-\mathrm{OH}\right), 4.06\left(\mathrm{q}, J=6.8 \mathrm{~Hz}, 4 \mathrm{H},-\mathrm{O}-\mathrm{PO}_{3}-\mathrm{CH}_{2}-\right)$, $3.82\left(\mathrm{t}, J=4.3 \mathrm{~Hz}, 2 \mathrm{H},-\mathrm{O}-\mathrm{PO}_{3}-\mathrm{CH}_{2}-\mathrm{CH}_{2}-\mathrm{OH}\right), 3.13(\mathrm{~b},-\mathrm{OH})$ $1.68\left(\mathrm{~m}, 4 \mathrm{H},-\mathrm{OPO}_{3}-\mathrm{CH}_{2}-\mathrm{CH}_{2}\right), 1.25\left(\mathrm{~s}, 32 \mathrm{H}\right.$, alkyl). ${ }^{13} \mathrm{C} \mathrm{NMR}$ $\left(75 \mathrm{MHz} \mathrm{CDCl}_{3}\right): \delta 69.66,68.21(\mathrm{~d}, J=6.1 \mathrm{~Hz}), 62.16,30.27(\mathrm{~d}, J=$ $7.0 \mathrm{~Hz}), 29.69(\mathrm{~d}, J=3.0 \mathrm{~Hz}), 29.56(\mathrm{~d}, J=4.7 \mathrm{~Hz}), 29.16,25.44 .{ }^{31} \mathrm{P}$ NMR (121 MHz, $\left.\mathrm{CDCl}_{3}\right): \delta 0.36$.

\subsection{Polymer Functionalization}

4.4.1. poly-1-terpy. Carbonyldiimidazole $(61 \mathrm{mg}, 0.22 \mathrm{mmol})$ was placed in a $25 \mathrm{~mL}$ Schlenk tube and dissolved in $0.5 \mathrm{~mL}$ of DMF. A solution of $2,2^{\prime}: 6^{\prime}, 2^{\prime \prime}$-terpyridine- $4^{\prime}$-carboxylic acid (35 mg, 0.22 $\mathrm{mmol}$ ) in $1.0 \mathrm{~mL}$ of DMF was added dropwise to the CDI solution with vigorous stirring. Evolving gas bubbles indicated the start of the reaction. The solution was stirred at room temperature for $30 \mathrm{~min}$ before heating to $60{ }^{\circ} \mathrm{C}$. Then, a solution of poly(2-hydroxyethyl eicosyl phosphate) $(89 \mathrm{mg}, 0.21 \mathrm{mmol})$ in $1.0 \mathrm{~mL}$ of DMF was added and the Schlenk tube was closed with a Teflon stopcock. The solution turned slightly purple over time. After it was stirred at $60^{\circ} \mathrm{C}$ for $72 \mathrm{~h}$, the hot solution was dropped into ice-cold methanol $\left(-18^{\circ} \mathrm{C}\right)$. poly1-terpy precipitated as a white solid. The precipitation step in methanol was repeated one more time. After centrifugation, the polymer was isolated and dried under reduced pressure. Yield: $48 \%$.

${ }^{1} \mathrm{H}$ NMR $\left(300 \mathrm{MHz}, \mathrm{CDCl}_{3}\right): \delta 9.01(\mathrm{~s}, 2 \mathrm{H}), 8.72(\mathrm{~d}, J=4.8 \mathrm{~Hz}$, $2 \mathrm{H}), 8.61(\mathrm{~d}, J=8.0 \mathrm{~Hz}, 2 \mathrm{H}), 7.86(\mathrm{t}, J=7.8 \mathrm{~Hz}, 2 \mathrm{H}), 7.40-7.30(\mathrm{~m}$, $2 \mathrm{H}), 4.64(\mathrm{t}, J=4.7 \mathrm{~Hz}, 2 \mathrm{H}), 4.41(\mathrm{q}, J=5.2,4.2 \mathrm{~Hz}, 2 \mathrm{H}), 4.05(\mathrm{q}, J$ $=6.8 \mathrm{~Hz}, 4 \mathrm{H}), 1.64(\mathrm{~h}, J=6.9,6.4 \mathrm{~Hz}, 4 \mathrm{H}), 1.31-1.15(\mathrm{~m}, 32 \mathrm{H}) .{ }^{13} \mathrm{C}$ NMR (75 MHz, $\left.\mathrm{CDCl}_{3}\right): \delta 165.12,156.64,155.34,149.32,139.30$, $136.89,124.19,121.25,120.39,68.12(\mathrm{~d}, J=6.2 \mathrm{~Hz}), 64.95,64.19$, $30.25(\mathrm{~d}, J=6.7 \mathrm{~Hz}), 29.63(\mathrm{dd}, J=11.9,5.4 \mathrm{~Hz}), 29.15,25.41 .{ }^{31} \mathrm{P}$ NMR (121 MHz, $\left.\mathrm{CDCl}_{3}\right): \delta 0.47,-0.93$.

\subsection{Polymer Crystal Assembly}

4.5.1. Solution-Grown Crystals of poly-1-terpy. Solutions of poly-1-terpy in ethyl acetate were prepared with concentrations of 1 and $0.1 \mathrm{mg} \mathrm{mL}-1$. Each solution was heated to $70{ }^{\circ} \mathrm{C}$ in a temperature-controlled oil bath for $1 \mathrm{~h}$ and slowly cooled to room temperature within $24 \mathrm{~h}$ using a programmed thermostat to ensure that each sample was cooled at the same speed. One drop of the resulting dispersion was drop-cast onto a carbon-coated TEM grid, the excess liquid was blotted off with a filter paper, and the specimen was allowed to dry under ambient conditions before TEM measurements were performed.

4.5.2. Supramolecular Folding of Polymer Platelets. Solutions of $\mathrm{Ni}(\mathrm{acac})_{2}$ in ethyl acetate were prepared with ratios of 2,20 , and $100 \mathrm{~mol} \%$ relative to the terpyridine units in poly-1-terpy. The solutions were added dropwise to the initial polymer crystal suspension. The final mixture was stirred for several seconds before sample preparation for TEM measurements was performed analogously to the initial poly-1-terpy crystals.

\section{ASSOCIATED CONTENT}

\section{Supporting Information}

The Supporting Information is available free of charge at https://pubs.acs.org/doi/10.1021/acspolymersau.1c00021.

Analytical and spectral characterization data (PDF) 


\section{AUTHOR INFORMATION}

\section{Corresponding Author}

Frederik R. Wurm - Max Planck Institute for Polymer Research, 55128 Mainz, Germany; Sustainable Polymer Chemistry, Department of Molecules and Materials, MESA+ Institute for Nanotechnology, Faculty of Science and Technology, Universiteit Twente, 7500 AE Enschede, The Netherlands; (1) orcid.org/0000-0002-6955-8489; Email: frederik.wurm@utwente.nl

\section{Authors}

Tobias P. Haider - Max Planck Institute for Polymer Research, 55128 Mainz, Germany

Oksana Suraeva - Max Planck Institute for Polymer Research, 55128 Mainz, Germany

Ingo Lieberwirth - Max Planck Institute for Polymer Research, 55128 Mainz, Germany; 이이.org/0000-0003$1323-524 \mathrm{X}$

Complete contact information is available at: https://pubs.acs.org/10.1021/acspolymersau.1c00021

\section{Notes}

The authors declare no competing financial interest.

\section{ACKNOWLEDGMENTS}

The authors thank the German Federal Ministry for Education and Research (BMBF) for their support of the program "Research for sustainable development (FONA)", "PlastX Plastics as a systemic risk for social-ecological supply systems" (grant number 01UU1603A). The authors thank the Deutsche Forschungsgemeinschaft WU 750/6-2 for funding.

\section{REFERENCES}

(1) Altintas, O., Fischer, T. S., Barner-Kowollik, C. Synthetic Methods Toward Single-Chain Polymer Nanoparticles. In SingleChain Polymer Nanoparticles; Wiley-VCH: 2017; pp 1-45.

(2) Hanlon, A. M.; Lyon, C. K.; Berda, E. B. What Is Next in SingleChain Nanoparticles? Macromolecules 2016, 49 (1), 2-14.

(3) Voet, D. V. J. Biochemistry; Wiley: 2004.

(4) Artar, M.; Huerta, E.; Meijer, E. W.; Palmans, A. R. A., Dynamic Single Chain Polymeric Nanoparticles: From Structure to Function. In Sequence-Controlled Polymers: Synthesis, Self-Assembly, and Properties; American Chemical Society: 2014; Vol. 1170, pp 313-325.

(5) Hu, M.; Butt, H.-J.; Landfester, K.; Bannwarth, M. B.; Wooh, S.; Thérien-Aubin, H. Shaping the Assembly of Superparamagnetic Nanoparticles. ACS Nano 2019, 13 (3), 3015-3022.

(6) Sindoro, M.; Yanai, N.; Jee, A.-Y.; Granick, S. Colloidal-Sized Metal-Organic Frameworks: Synthesis and Applications. Acc. Chem. Res. 2014, 47 (2), 459-469.

(7) Boott, C. E.; Nazemi, A.; Manners, I. Synthetic Covalent and Non-Covalent 2D Materials. Angew. Chem., Int. Ed. 2015, 54 (47), 13876-13894.

(8) Pearce, S.; He, X.; Hsiao, M.-S.; Harniman, R. L.; MacFarlane, L. R.; Manners, I. Uniform, High-Aspect-Ratio, and Patchy 2D Platelets by Living Crystallization-Driven Self-Assembly of Crystallizable Poly(ferrocenyldimethylsilane)-Based Homopolymers with Hydrophilic Charged Termini. Macromolecules 2019, 52 (16), 6068-6079.

(9) Hudson, Z. M.; Boott, C. E.; Robinson, M. E.; Rupar, P. A.; Winnik, M. A.; Manners, I. Tailored hierarchical micelle architectures using living crystallization-driven self-assembly in two dimensions. Nat. Chem. 2014, 6, 893.

(10) Qiu, H.; Gao, Y.; Boott, C. E.; Gould, O. E. C.; Harniman, R. L.; Miles, M. J.; Webb, S. E. D.; Winnik, M. A.; Manners, I. Uniform patchy and hollow rectangular platelet micelles from crystallizable polymer blends. Science 2016, 352 (6286), 697-701.

(11) Mohd Yusoff, S. F.; Hsiao, M.-S.; Schacher, F. H.; Winnik, M. A.; Manners, I. Formation of Lenticular Platelet Micelles via the Interplay of Crystallization and Chain Stretching: Solution SelfAssembly of Poly(ferrocenyldimethylsilane)-block-poly(2-vinylpyridine) with a Crystallizable Core-Forming Metalloblock. Macromolecules 2012, 45 (9), 3883-3891.

(12) Nazemi, A.; He, X.; MacFarlane, L. R.; Harniman, R. L.; Hsiao, M.-S.; Winnik, M. A.; Faul, C. F. J.; Manners, I. Uniform "Patchy" Platelets by Seeded Heteroepitaxial Growth of Crystallizable Polymer Blends in Two Dimensions. J. Am. Chem. Soc. 2017, 139 (12), 44094417.

(13) Inam, M.; Jones, J. R.; Pérez-Madrigal, M. M.; Arno, M. C.; Dove, A. P.; O’Reilly, R. K. Controlling the Size of Two-Dimensional Polymer Platelets for Water-in-Water Emulsifiers. ACS Cent. Sci. 2018, 4 (1), 63-70.

(14) Bassett, D. C.; Frank, F. C.; Keller, A. Some new habit features in crystals of long chain compounds part IV. the fold surface geometry of monolayer polyethylene crystals and its relevance to fold packing and crystal growth. Philos. Mag. 1963, 8 (94), 1753-1787.

(15) Fischer, E. W.; Hinrichsen, G. Schmelz- und Rekristallisationsvorgänge bei Polyäthylen-Einkristallen. Colloid Polym. Sci. 1966 213 (1-2), 93-109.

(16) Ortmann, P.; Trzaskowski, J.; Krumova, M.; Mecking, S. Precise Microstructure Self-Stabilized Polymer Nanocrystals. ACS Macro Lett. 2013, 2 (2), 125-127.

(17) Schnitte, M.; Staiger, A.; Casper, L. A.; Mecking, S. Uniform shape monodisperse single chain nanocrystals by living aqueous catalytic polymerization. Nat. Commun. 2019, 10 (1), 2592.

(18) Haider, T.; Suraeva, O.; O’Duill, M. L.; Mars, J.; Mezger, M.; Lieberwirth, I.; Wurm, F. R. Controlling the crystal structure of precisely spaced polyethylene-like polyphosphoesters. Polym. Chem. 2020, 11 (20), 3404-3415.

(19) Dong, B.; Miller, D. L.; Li, C. Y. Polymer Single Crystal As Magnetically Recoverable Support for Nanocatalysts. J. Phys. Chem. Lett. 2012, 3 (10), 1346-1350.

(20) Dong, B.; Zhou, T.; Zhang, H.; Li, C. Y. Directed Self-Assembly of Nanoparticles for Nanomotors. ACS Nano 2013, 7 (6), 51925198.

(21) Han, L.; Wang, M.; Jia, X.; Chen, W.; Qian, H.; He, F. Uniform two-dimensional square assemblies from conjugated block copolymers driven by $\pi-\pi$ interactions with controllable sizes. Nat. Commun. 2018, 9 (1), 865

(22) Shunmugam, R.; Gabriel, G. J.; Aamer, K. A.; Tew, G. N. Metal-Ligand-Containing Polymers: Terpyridine as the Supramolecular Unit. Macromol. Rapid Commun. 2010, 31 (9-10), 784793.

(23) Hofmeier, H.; Schubert, U. S. Recent developments in the supramolecular chemistry of terpyridine-metal complexes. Chem. Soc. Rev. 2004, 33 (6), 373-399.

(24) Whittell, G. R.; Hager, M. D.; Schubert, U. S.; Manners, I. Functional soft materials from metallopolymers and metallosupramolecular polymers. Nat. Mater. 2011, 10 (3), 176-188.

(25) Winter, A.; Schubert, U. S. Synthesis and characterization of metallo-supramolecular polymers. Chem. Soc. Rev. 2016, 45 (19), 5311-5357.

(26) Gallina, M. E.; Bergamini, G.; Di Motta, S.; Sakamoto, J.; Negri, F.; Ceroni, P. Luminescent multi-terpyridine ligands: towards $2 \mathrm{D}$ polymer formation in solution. Photochemical \& Photobiological Sciences 2014, 13 (7), 997-1004.

(27) Steinbach, T.; Wurm, F. R. Poly(phosphoester)s: A New Platform for Degradable Polymers. Angew. Chem., Int. Ed. 2015, 54 (21), 6098-6108.

(28) Bauer, K. N.; Tee, H. T.; Velencoso, M. M.; Wurm, F. R. Mainchain poly(phosphoester)s: History, syntheses, degradation, bio-and flame-retardant applications. Prog. Polym. Sci. 2017, 73, 61-122. 
(29) Wagener, K. B.; Boncella, J. M.; Nel, J. G. Acyclic diene metathesis (ADMET) polymerization. Macromolecules 1991, 24 (10), 2649-2657.

(30) Zheng, Y.-R.; Tee, H. T.; Wei, Y.; Wu, X.-L.; Mezger, M.; Yan, S.; Landfester, K.; Wagener, K.; Wurm, F. R.; Lieberwirth, I. Morphology and Thermal Properties of Precision Polymers: The Crystallization of Butyl Branched Polyethylene and Polyphosphoesters. Macromolecules 2016, 49 (4), 1321-1330.

(31) Cankaya, A.; Steinmann, M.; Bülbül, Y.; Lieberwirth, I.; Wurm, F. R. Side-chain poly(phosphoramidate)s via acyclic diene metathesis polycondensation. Polym. Chem. 2016, 7 (31), 5004-5010.

(32) Markwart, J. C.; Suraeva, O.; Haider, T.; Lieberwirth, I.; Graf, R.; Wurm, F. R. Defect engineering of polyethylene-like polyphosphoesters: solid-state NMR characterization and surface chemistry of anisotropic polymer nanoplatelets. Polym. Chem. 2020, 11 (45), 7235-7243.

(33) Busch, H.; Schiebel, E.; Sickinger, A.; Mecking, S. UltralongChain-Spaced Crystalline Poly(H-phosphonate)s and Poly(phenylphosphonate)s. Macromolecules 2017, 50 (20), 7901-7910.

(34) Tee, H. T.; Lieberwirth, I.; Wurm, F. R. Aliphatic Long-Chain Polypyrophosphates as Biodegradable Polyethylene Mimics. Macromolecules 2019, 52 (3), 1166-1172.

(35) Reneker, D. H. Localized deformation of lamellar polyethylene crystals. J. Polym. Sci., Part A: Gen. Pap. 1965, 3 (3), 1069-1077. 